\title{
Improved myocardial protection in the failing heart by selective endothelin-A receptor blockade
}

\author{
Karola Trescher, MD, ${ }^{\mathrm{a}, \mathrm{b}}$ Michael Bauer, MD, ${ }^{\mathrm{b}}$ Wolfgang Dietl, MD, ${ }^{\mathrm{b}}$ Seth Hallström, PhD, ${ }^{\mathrm{c}}$ Nikolaus Wick, MD, ${ }^{\mathrm{d}}$ \\ Margarita Wolfsberger, MD, ${ }^{\mathrm{e}}$ Robert Ullrich, PhD, ${ }^{\mathrm{d}}$ Günther Jürgens, $\mathrm{PhD},{ }^{\mathrm{c}}$ Ernst Wolner, MD, ${ }^{\mathrm{b}}$ and Bruno K. Podesser, MD ${ }^{\mathrm{a}, \mathrm{b}}$
}

Objective: Ischemia/reperfusion injury caused by cardioplegic arrest is still a major challenge in patients with reduced left ventricular function. We investigated the effect of chronic versus acute administration of the selective endothelin-A receptor antagonist (ERA) TBC-3214Na during ischemia/reperfusion in failing hearts.

Methods: Male Sprague-Dawley rats underwent coronary ligation. Three days after myocardial infarction (MI), 19 randomly assigned animals (ERA chronic) were administered TBC-3214Na continuously with their drinking water, $29 \mathrm{MI}$ rats received placebo, and 3 rats died during the observation period. Six weeks after infarction, hearts were evaluated in a blood-perfused working heart model during 60 minutes of ischemia and 30 minutes of reperfusion. In $14 \mathrm{MI}$ rats, TBC-3214Na (ERA acute) was added to the cardioplegic solution during ischemia. Thirteen MI rats served as control.

Results: At a similar infarct size, postischemic recovery of cardiac output (ERA chronic: $91 \% \pm 10 \%$, ERA acute: $86 \% \pm 11 \%$ vs control: $52 \% \pm 15 \% ; P<.05$ ) and external heart work (ERA chronic: $90 \% \pm 10 \%$, ERA acute: $85 \% \pm 13 \%$ vs control: $51 \% \pm 17 \% ; P<.05)$ was significantly enhanced in both TBC$3214 \mathrm{Na}$-treated groups whereas recovery of coronary flow was only improved in ERA acute rats (ERA acute: $121 \% \pm 23 \%$ vs ERA chronic: $75 \% \pm 13 \%$; control: $64 \% \pm 15 \% ; P<.05$ ). Blood gas measurements showed enhanced myocardial oxygen delivery and consumption with acute TBC-3214Na therapy. Additionally, highenergy phosphates (phosphocreatine) were significantly higher and transmission electron microscopy revealed less ultrastructural damage under acute TBC-3214Na administration.

Conclusion: Acute endothelin-A receptor blockade is superior to chronic blockade in attenuating ischemia/reperfusion injury in failing hearts. Therefore, acute endothelin-A receptor blockade might be an interesting option for patients with heart failure undergoing cardiac surgery.

Supplemental material is available online.

Cardiac surgery is confronted with an increasing number of patients with severe heart failure. Especially in patients with reduced left ventricular (LV) function, poor postischemic recovery owing to intraoperative ischemia/reperfusion (I/R) injury is a major challenge to surgeons and anesthesiologists.

Currently used standard cardioplegic solutions provide a high level of myocardial protection in elective cardiac operations and in patients with an average risk profile. For high-risk patients with severely reduced LV function, im-

\footnotetext{
From the Department of Cardiac Surgery, LK St Poelten; ; the Ludwig Boltzmann Cluster for Cardiovascular Research'; the Institute of Physiological Chemistry, Center of Physiological Medicine, Medical University Graz ; and the Departments of Pathology ${ }^{\mathrm{d}}$ and Pediatrics, ${ }^{\mathrm{e}}$ Vienna Medical University, Vienna, Austria.

Received for publication April 4, 2008; revisions received Oct 6, 2008; accepted for publication Oct 27, 2008.

Address for reprints: Bruno K. Podesser, MD, Ludwig Boltzmann Cluster for Cardiovascular Research, C/O Core Unit for Biomedical Research, Medical University of Vienna, Vienna General Hospital, Währinger Gürtel 18-20, 1090 Vienna, Austria (E-mail: bruno.podesser@meduniwien.ac.at).

J Thorac Cardiovasc Surg 2009;137:1005-11

$0022-5223 / \$ 36.00$

Copyright (c) 2009 by The American Association for Thoracic Surgery

doi:10.1016/j.jtcvs.2008.10.037
}

provements in cardioprotection seem to be more crucial. A potential target for a further increase of cardioprotection may lie in the endothelin system. ${ }^{1}$ On the one hand, endothelin-1 (ET-1), the major isoform, is responsible for the progression and maintenance of cardiac remodeling after myocardial infarction (MI), leading to the chronic process of heart failure; on the other hand, ET-1 plays an important role in acute I/R injury. ${ }^{2,3}$ The effects of ET-1 are mediated by two receptor subtypes: $\mathrm{ET}_{\mathrm{A}}$ receptors induce vasoconstriction and cellular proliferation and are mainly located in the medial smooth muscle cell layers of blood vessels, as well as the atrial and ventricular myocardium. ${ }^{4} \mathrm{ET}_{\mathrm{B}}$ receptors are located on endothelial cells and to some extent on vascular smooth muscle cells and macrophages. Activation of the $\mathrm{ET}_{\mathrm{B}}$ receptor leads to the release of nitric oxide and prostacyclin and prevents apoptosis. ${ }^{5}$ Several experimental studies revealed in both global ${ }^{6-9}$ and local $^{10} \mathrm{I} / \mathrm{R}$ a positive effect of selective $\mathrm{ET}_{\mathrm{A}}$ and combined $\mathrm{ET}_{\mathrm{A}} / \mathrm{ET}_{\mathrm{B}}$ receptor blockade on hemodynamic performance, endothelial function, MI size, inflammatory response, and oxidative stress. All these results were obtained for healthy hearts with normal cardiac function before $\mathrm{I} / \mathrm{R}$ injury.

We tested two hypotheses: (1) Does acute administration of the selective $\mathrm{ET}_{\mathrm{A}}$ receptor antagonist (ERA) TBC$3214 \mathrm{Na}$ as adjunct to standard blood cardioplegic solution improve postischemic recovery of cardiac function and 


$$
\begin{aligned}
& \text { Abbreviations and Acronyms } \\
& \text { ADP }=\text { adenosine diphosphate } \\
& \text { AMP }=\text { adenosine monophosphate } \\
& \text { ATP }=\text { adenosine triphosphate } \\
& \mathrm{CO}=\text { cardiac output } \\
& \text { ERA }=\text { endothelin-A receptor antagonist } \\
& \mathrm{ET}=\text { endothelin } \\
& \mathrm{I} / \mathrm{R} \quad \text { ischemia/reperfusion } \\
& \mathrm{LV}=\text { left ventricle } \\
& \mathrm{MDO}{ }_{2}=\text { myocardial oxygen delivery } \\
& \mathrm{MI}=\text { myocardial infarction } \\
& \mathrm{MVO} \mathrm{P}_{2}=\text { myocardial oxygen consumption } \\
& \mathrm{PCr}=\text { phosphocreatine } \\
& \mathrm{WH} \quad=\text { working heart mode } \\
& \mathrm{rWH}=\text { working heart mode during reperfusion }
\end{aligned}
$$

metabolism in failing rat hearts. (2) Additionally, one group of failing hearts, chronically treated with ERA, underwent the same I/R protocol to test whether there is any positive impact of chronic $\mathrm{ET}_{\mathrm{A}}$ blockade in the acute setting of $\mathrm{I} / \mathrm{R}$ injury.

\section{METHODS \\ MI Model}

MI was induced in 48 male Sprague-Dawley rats by ligation of the left anterior descending coronary artery as described previously. ${ }^{11}$ All animals had free access to standard rat chow and water during the 6-week observation period and received humane care in compliance with the European Convention on Animal Care. The experiments were approved by the Committee for Animal Research, Vienna Medical University.

\section{Experimental Protocol and Perfusion System}

Three days after MI, the surviving animals were randomized into two groups. The first group (ERA chronic; $n=19$ ) of animals received the $\mathrm{ET}_{\mathrm{A}}$ selective receptor blocker TBC-3214Na (45 mg/kg body weight), whereas the second group (MI; $n=29$ ) received a placebo. Both TBC$3214 \mathrm{Na}$ and placebo were added to the drinking water during the 6-week observation period. In the observation period, 1 rat in the ERA chronic group and 2 in the MI group died.

The $27 \mathrm{MI}$ rats of the placebo group were randomly divided for the acute experiments. Fourteen rats received TBC-3214Na as adjunct to cardioplegic solution starting with the induction of cardiac arrest (ERA acute; $n=14$ ). In the other MI rats (control; $\mathrm{n}=13$ ), as well as in the ERA chronic group $(\mathrm{n}=$ 18), standard cardioplegic solution was used without adjunct. Primarily, the effect of TBC-3214Na on the change of coronary flow was assessed in the Langendorff model. Starting with $10 \mathrm{mg} / \mathrm{kg}$ body weight, we enhanced the dosage stepwise in 5-mg increments. At $30 \mathrm{mg} / \mathrm{kg}$, a significant change in coronary blood flow was detected as compared with baseline. This dose was chosen for intracoronary application.

Six weeks after MI, in vivo hemodynamic measurements were performed by transthoracic echocardiography. Then the rats were heparinized with $200 \mathrm{IU} / \mathrm{kg}$ intravenously and the hemodynamic performance of the excised hearts was evaluated on an isolated red-cell perfused working heart system (Hugo Sachs Elektronik, Freiburg, Germany), as described by Podesser and associates. ${ }^{12}$ The perfusion experiment was conducted according to the standardized time schedule depicted in Figure 1. In the Langendorff mode (LD before ischemia, rLD during reperfusion), the coronary arteries

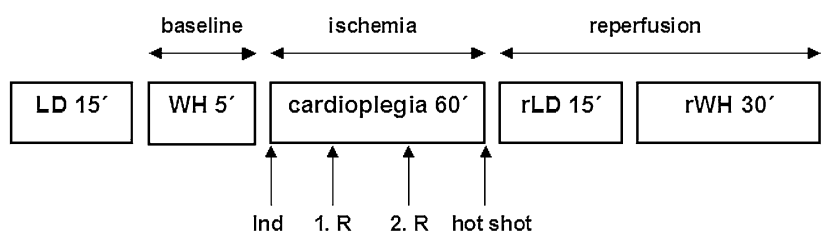

FIGURE 1. Time schedule of the perfusion protocol. $L D$, Langendorff mode; $W H$, Working heart mode; $r L D$, Langendorff mode during reperfusion; $r W H$, Working heart mode during reperfusion. Cardioplegic arrest was induced ( $I$, induction) by cold blood cardioplegia according to Buckberg. Cardioplegia continued with two cold reinfusions $(1 . R, 2 . R)$ and was finished by a "hot shot."

were perfused at a constant pressure of $70 \mathrm{~mm} \mathrm{Hg}$. After cannulation of the left atrium for conversion to the working heart mode (WH), the LV was ejecting against a predefined afterload corresponding to a mean aortic pressure of $70 \mathrm{~mm} \mathrm{Hg}$. For induction of cardioplegic arrest, cold blood cardioplegic solution according to Buckberg (Buckberg Kardioplegie; Köhler Chemie GmbH, Alsbach-Hähnlein, Germany; 4:1 ratio of perfusate to Buckberg's stock solution, $4^{\circ} \mathrm{C}$ at a mean aortic pressure of $50 \mathrm{~mm} \mathrm{Hg}$ ) was used.

After evaluation on the isolated heart, 5 randomly picked animals per group were taken to evaluate infarct size. In the other hearts, biochemical, histologic, and ultrastructural analyses were performed.

\section{Drugs}

TBC-3214Na is both an orally active and parenterally applicable selective $\mathrm{ET}_{\mathrm{A}}$ receptor antagonist. It is a follow-on candidate of sitaxsentan (TBC-11251) with a $25 \%$ higher oral bioavailability and a half-life of more than 4 hours. The drug was kindly provided by Encysive Pharmaceuticals, Houston, Texas.

\section{In Vivo Hemodynamic Data Acquisition}

Six weeks after MI, the animals were evaluated by transthoracic echocardiography as described previously. ${ }^{11}$ Imaging was done by an ultrasonographer experienced in rodent imaging and blinded to the study groups.

\section{Ex Vivo Hemodynamic Data Acquisition}

Hemodynamic data were obtained from the predefined time points: WH5 (baseline values), which indicates the time point measured in minutes after conversion from Langendorff perfusion to the working heart mode before ischemia, and rWH5, rWH10, rWH15, rWH25, rWH30, which stand for the respective time points in the reperfusion period.

All hemodynamic values were registered as mean values derived from the respective pressure and flow tracings. The following parameters were assessed: cardiac output (CO, $\mathrm{mL} / \mathrm{min}$ ) identical to left atrial flow (Flowmeter Narcomatic RT-500, Narco Biosystems) in a closed circuit perfusion; external heart work $(\mathrm{g} \times \mathrm{m} / \mathrm{min}$, calculated as $\mathrm{CO} \times \mathrm{LV}$ systolic pressure), indicating pressure volume work performed per minute; and coronary flow $(\mathrm{mL} / \mathrm{min})$. As mean aortic pressure remained constant during all phases of perfusion, variations in coronary flow primarily reflect alterations in coronary resistance, allowing assessment of function of microvasculature. LV systolic pressure was measured by a high-fidelity MicroTip catheter (Millar SP-407; Millar Instruments, Inc, Houston, Tex) introduced into the LV. Diastolic compliance was assessed by measurement of diastolic left atrial pressure. Three hearts in the ERA chronic, 2 in the ERA acute, and 1 in the control group did not reach sufficient $\mathrm{CO}$ at baseline WH5 (CO >15 $\mathrm{mL} \cdot \min ^{-1} \cdot \mathrm{g}^{-1}$ ) and were excluded from further analysis. The hemodynamic data of the reperfusion period are presented as recovery (mean percentage of baseline values) to adjust for differences in baseline between groups. 
TABLE 1. Echocardiographic, baseline working heart, and morphometric data

\begin{tabular}{|c|c|c|c|}
\hline & Control $(n=12)$ & ERA chronic $(n=15)$ & ERA acute $(n=12)$ \\
\hline \multicolumn{4}{|c|}{ Part 1: Echocardiographic data } \\
\hline LVEDD (cm) & $1.14 \pm 0.05$ & $1.01 \pm 0.01 *$ & $1.2 \pm 0.04$ \\
\hline $\operatorname{LVESD}(\mathrm{cm})$ & $1.01 \pm 0.06$ & $0.82 \pm 0.01 *$ & $1.05 \pm 0.02$ \\
\hline $\mathrm{EF}$ & $0.28 \pm 0.04$ & $0.44 \pm 0.01 *$ & $0.30 \pm 0.02$ \\
\hline \multicolumn{4}{|c|}{ Part 2: Baseline working heart data } \\
\hline $\mathrm{CF}\left(\mathrm{mL} \cdot \mathrm{min}^{-1} \cdot \mathrm{g}^{-1} \mathrm{HW}\right)$ & $2.72 \pm 0.35$ & $2.71 \pm 0.48$ & $2.89 \pm 0.51$ \\
\hline $\mathrm{CO}\left(\mathrm{mL} \cdot \min ^{-1} \cdot \mathrm{g}^{-1} \mathrm{HW}\right)$ & $20.06 \pm 3.68$ & $32.94 \pm 2.86^{*}$ & $22.98 \pm 4.62$ \\
\hline $\mathrm{EHW}(\mathrm{g} \times \mathrm{m} / \mathrm{min})$ & $3365 \pm 427$ & $5963 \pm 737 *$ & $3862 \pm 613$ \\
\hline Part 3: Morphometric data & Control $(\mathbf{n}=\mathbf{5})$ & ERA chronic $(n=5)$ & ERA acute $(n=5)$ \\
\hline BDW (g) & $446.6 \pm 27.4$ & $440.1 \pm 38.1$ & $439.6 \pm 24.9$ \\
\hline Infarct size $(\%)$ & $46.2 \pm 3.7$ & $47.5 \pm 2.1$ & $45.8 \pm 3.5$ \\
\hline Total HW (g) & $2.24 \pm 0.34$ & $1.95 \pm 0.19$ & $2.34 \pm 0.38$ \\
\hline $\mathrm{LV} / \mathrm{BDW}$ & $3.28 \pm 0.11$ & $2.68 \pm 0.18^{*}$ & $3.34 \pm 0.2$ \\
\hline
\end{tabular}

$L V E D D$, Left ventricular end-diastolic diameter; $L V E S D$, left ventricular end-systolic diameter; $E F$, ejection fraction; $C F$, coronary flow; HW, heart weight; $C O$, cardiac output; $E H W$, external heart work (calculated as $\mathrm{CO} \times \mathrm{LV}$ systolic pressure); BDW, body weight; $\mathrm{LV}$, left ventricular. Data are presented as mean $\pm \mathrm{SEM}$. $* P<.05$ vs both control and ERA acute group.

\section{Morphometric and Histologic Evaluation}

To evaluate the extent of heart failure, in addition to echocardiography, we determined infarct size and myocardial hypertrophy. Therefore, at the end of the ex vivo experiment, 5 random hearts from each group underwent morphometric examination. ${ }^{13}$ Infarct size was expressed as the ratio of the infarct region to total LV mass.

All other hearts (ERA acute $\mathrm{n}=7$, ERA chronic $\mathrm{n}=10$, control $\mathrm{n}=7$ ) underwent two different protocols for tissue processing at the end of the isolated heart perfusion. This enabled the evaluation of both biochemical and histologic changes in one heart: Hearts were switched back to the Langendorff mode again after the reperfusion period was finished. The first protocol was used to obtain samples for the measurement of high-energy phosphates: a freeze-clamped specimen of the noninfarcted septum close to the apex was taken from the beating heart and immediately frozen in liquid nitrogen. The second protocol was used to determine ultrastructural damage of myocardial tissue by electron microscopy: after the septal biopsy, the heart was flushed with Krebs-Henseleit buffer again to wash out erythrocytes. Then a small tissue sample from the upper part of the septum was fixed in a $4 \%$ buffered paraformaldehyde solution containing $0.1 \%$ glutaraldehyde for further histologic examination. Electron microscopy was performed according to standard procedures described before. ${ }^{14}$

\section{Biochemical Evaluation}

Arterial and coronary sinus blood samples were collected at time point WH5 before ischemia and rWH15 during reperfusion. Blood gas analysis was performed and the following parameters were calculated: myocardial oxygen consumption $\left(\mathrm{MVO}_{2}\right)$, myocardial oxygen delivery $\left(\mathrm{MDO}_{2}\right)$, and cumulative lactate according to the formula described by Dworschak and associates. ${ }^{15}$ The high-energy phosphates adenosine monophosphate (AMP), adenosine diphosphate (ADP), adenosine triphosphate (ATP), and phosphocreatine ( $\mathrm{PCr}$ ) were analyzed by high-performance liquid chromatography as described previously. ${ }^{16}$ Energy charge (EC) was calculated according to the following formula: $\mathrm{EC}=(\mathrm{ATP}+1 / 2 \mathrm{ADP}) /(\mathrm{ATP}+\mathrm{ADP}+$ AMP).

\section{Statistical Analysis}

All data are expressed as mean \pm SEM. Analysis of variance was performed with GraphPad Prism Statistical Software 4.0 (GraphPad Software, Inc, La Jolla, Calif). Whenever significance was indicated, Bonferroni multiple comparison analysis was performed to compare between groups.

\section{RESULTS}

\section{Animal Characteristics}

The first part of Table 1 and Table E1 summarizes the results of in vivo hemodynamic measurements. In transthoracic echocardiography, 42 days after $\mathrm{MI}$ the animals receiving TBC-3214Na chronically with their drinking water showed less systolic and diastolic LV dilatation $(P<.05)$ than did the control and ERA acute groups. Consequently, ejection fraction as a marker of LV function was higher in the chronic treatment group $(P<.05)$ than in the control and ERA acute groups.

The second part of Table 1 shows baseline hemodynamic findings on the working heart apparatus at time point 5 Minutes (WH5). Comparison of preischemic baseline values recorded during WH5 confirmed the echocardiographic evaluation indicating a superior LV function in the chronic treatment group in comparison with the control and ERA acute groups, whereas there was no difference between control and ERA acute groups at baseline. In coronary flow per gram heart weight, there was no difference in preischemic baseline values among all groups.

The third part of Table 1 summarizes the morphometric characteristics of the 5 representative hearts per group. At a comparable infarct size, the difference in LV to body weight ratio reached statistical significance in the ERA chronic group versus the control and ERA acute groups $(P<.05)$, indicating reduced LV hypertrophy with chronic ERA treatment.

\section{Ex Vivo Hemodynamic Data}

Comparison of postischemic recovery of hemodynamic function showed the following results (Figure 2 and Figure E1): Recovery of coronary flow was significantly enhanced in the ERA acute group compared with both the ERA chronic and control groups $(P<.01$; Figure $2, A)$. For left 

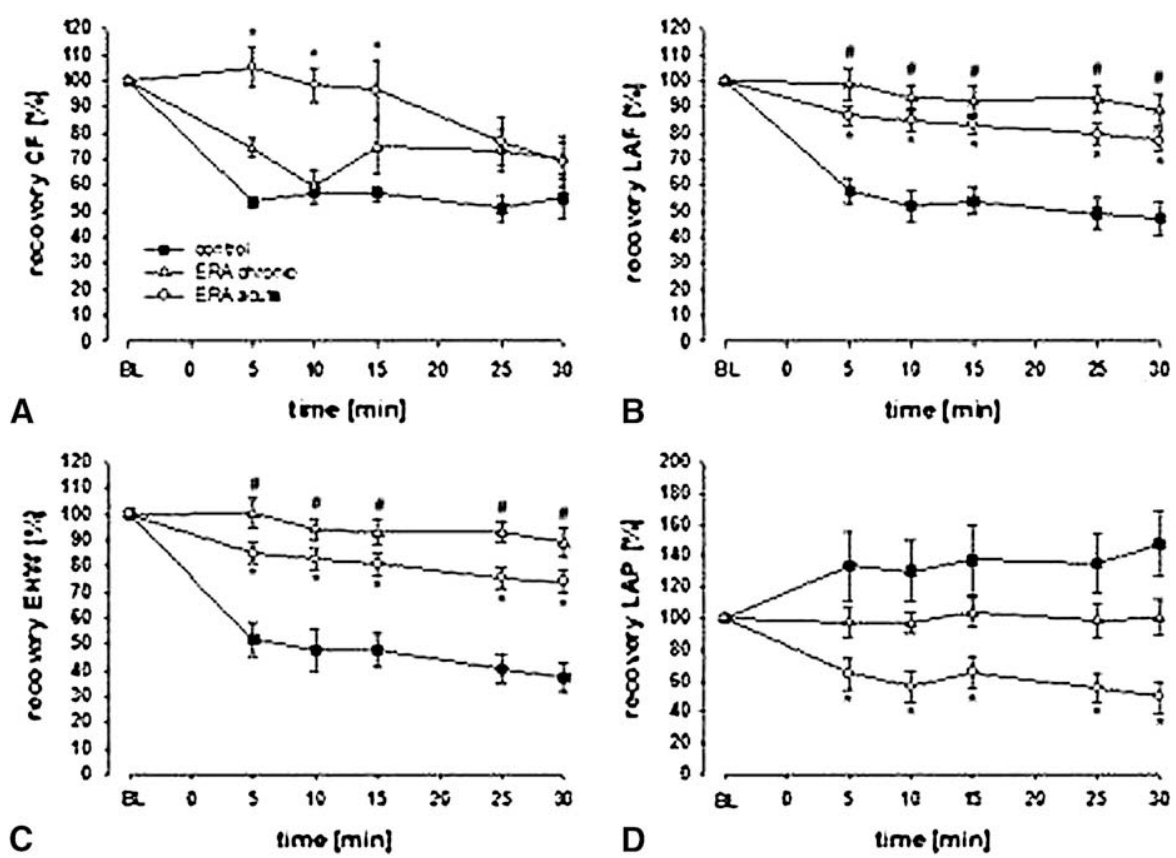

FIGURE 2. Ex vivo hemodynamic measurements. Data of the reperfusion period are presented as recovery values (percentage of baseline). A, Recovery of coronary flow $(C F)$ ERA acute versus both ERA chronic and control groups, ${ }^{*} P<.01$ ( $B L$, baseline). B, Recovery of cardiac output ( $L A F$, left atrial flow) ERA acute versus control group, ${ }^{*} P<.01$; ERA chronic versus control group, $\# P<.01$. C, Recovery of external heart work $(E H W)$ (cardiac output $\times$ LV systolic pressure). ERA acute versus control group, ${ }^{*} P<.01$; ERA chronic versus control group; $\# P<.01$. D, Recovery of diastolic left atrial pressure $(L A P)$, $* P<.01$ ERA acute versus control group. All data are presented as mean \pm SEM.

atrial flow, which is identical to $\mathrm{CO}$ in a closed circuit perfusion, both treatment groups showed improved recovery versus control $(P<.01$; Figure $2, B)$. For LV systolic pressure, there was only a trend toward improved recovery in the ERA acute group, which did not reach statistical significance (data not shown). Recovery of external heart work again was significantly higher in both the ERA acute and ERA chronic groups compared with the control group $(P<.01$ vs control; Figure $2, C)$. Postischemic left atrial pressure as an indicator for LV compliance was significantly reduced in the ERA acute group compared with the control group $(P<.01)$, whereas there was no significant difference between the ERA chronic group and the control group (Figure 2,D).

\section{Histologic Evaluation}

Ultrastructural changes were evaluated in 5 specimens per group in 3 randomly selected fields in a blindfold manner and graded according to the criteria of Schaper and colleagues. ${ }^{17}$ In the control group, 4 of 5 specimens showed severe to irreversible ischemic injury. In 1 specimen damage was graded as moderate to severe. In the chronic treatment group, 2 specimens showed severe to irreversible injury, and 3 specimens showed moderate to severe ischemic damage. In the acute treatment group, none of the hearts showed severe to irreversible injury, 3 hearts showed moderate ischemic damage, and 2 hearts showed slight to moderate damage. Representative micrographs are depicted in Figure 3.

\section{Biochemical Data}

There were no significant differences in preischemic $\mathrm{MVO}_{2}$ between the control group and the ERA acute group. However, by comparison, $\mathrm{MVO}_{2}$ was significantly lower in the ERA chronic group (Table 2). During reperfusion, $\mathrm{MVO}_{2}$ did not decrease significantly compared with the preischemic values in all 3 groups. In the ERA chronic group, $\mathrm{MVO}_{2}$ remained low during reperfusion compared with the control and ERA acute groups, with no significant difference between the control and ERA acute group.

Before ischemia, $\mathrm{MDO}_{2}$ was comparable among the 3 groups. During reperfusion, there was no difference between the control and ERA chronic groups, whereas in ERA acute $\mathrm{MDO}_{2}$ was significantly increased, indicating improved coronary perfusion $(P<.01)$.

At baseline, cumulative lactate did not differ among all groups; after ischemia, cumulative lactate was significantly reduced in both the ERA acute and ERA chronic groups compared with the control group.

Postischemic evaluation of high-energy phosphates revealed the superior preservation of acutely ERA treated hearts (Figure 4, A). Phosphocreatine, the buffering energy source for ATP in situations of energy demand, was significantly higher only in the acutely ERA treated hearts compared with the control hearts $(P<.01)$, whereas ATP was significantly elevated in both the acute and chronic treatment 

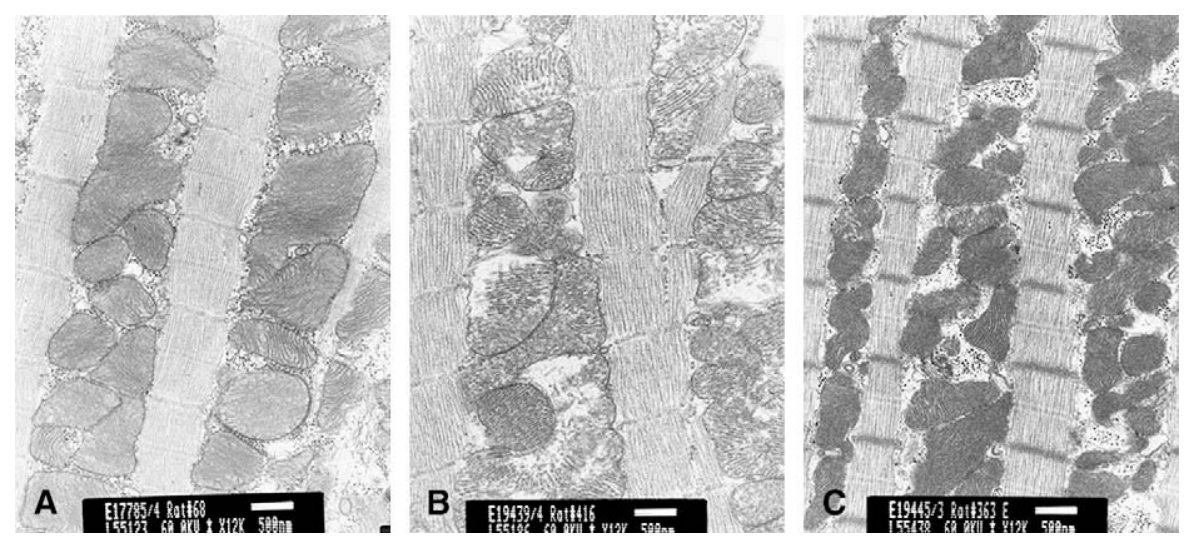

FIGURE 3. Representative micrographs of transmission electron microscopy at the end of reperfusion. A, Control. B, ERA chronic. C, ERA acute. In A and $\mathrm{B}$, swelling and disruption of mitochondrial cristae and myofilaments indicate severe ischemic injury. In $\mathrm{C}$, the integrity of mitochondria and myofilaments are preserved by TBC-3214 treatment during I/R.

groups compared with the control group $(P<.05)$. Energy charge was also significantly higher only in the ERA acute group compared with the control group $(0.82 \pm 0.01 \mathrm{vs}$ $0.73 \pm 0.01 ; P<.01)$, whereas the ERA chronic group $(0.80 \pm 0.02)$ did not reach significance (Figure $4, B)$. The ATP/ADP and PCr/ATP ratios showed a similar picture (ATP/ADP: ERA acute group: $3.41 \pm 0.19$ vs control: $1.50 \pm 0.27 ; P<.01$; ERA chronic: $2.95 \pm 0.28$ vs control; $P<.05$; PCr/ATP: ERA acute: $2.23 \pm 0.10$ vs control: 0.78 $\pm 0.21 ; P<.01$; ERA chronic group: $1.72 \pm 0.35$ control; $P=$ not significant).

\section{DISCUSSION}

The aim of the present study was to evaluate the effect of long-term versus acute administration of a selective $\mathrm{ET}_{\mathrm{A}}$-receptor blocker in failing hearts under the conditions of I/R. When comparing hemodynamic recovery between chronic and acute administration of TBC-3214Na, there is an equal protection with either strategy used with the exception of coronary flow. However, energy metabolism and ultrastructural damage data reveal that only acute $\mathrm{ET}_{\mathrm{A}}$-receptor blockade provides superior myocardial protection compared with chronic blockade. These data suggest that improvement of coronary blood flow is responsible for superior protection by preventing vasoconstriction caused by endothelial dysfunction.

In healthy hearts, several studies using both $\mathrm{ET}_{\mathrm{A}}$ selective and combined $\mathrm{ET}_{\mathrm{A}} / \mathrm{ET}_{\mathrm{B}}$ receptor antagonists demonstrated a protective role in $\mathrm{I} / \mathrm{R}$. In a model of local $\mathrm{I} / \mathrm{R}$, by ligation and subsequent reperfusion of the left anterior descending coronary artery, a reduction of infarct size and oxidative damage ${ }^{10}$ could be achieved by ERA. In isolated heart preparations similar to our model, different receptor antagonists led to an improvement of systolic and diastolic cardiac function, ${ }^{6}$ coronary artery blood flow, ${ }^{7}$ endothelial function, and to a reduction of the no-reflow area $^{8}$ and ischemic contracture. $^{9}$
TABLE 2. Biochemical data

\begin{tabular}{|c|c|c|c|}
\hline & $\begin{array}{l}\text { Control } \\
(\mathrm{n}=12)\end{array}$ & $\begin{array}{c}\text { ERA chronic } \\
\quad(n=15)\end{array}$ & $\begin{array}{l}\text { ERA acute } \\
(\mathrm{n}=12)\end{array}$ \\
\hline \multicolumn{4}{|l|}{$\mathrm{MVO}_{2}$} \\
\hline Baseline & $0.06 \pm 0.01$ & $0.03 \pm 0.01 *$ & $0.06 \pm 0.00 \ddagger$ \\
\hline Reperfusion & $0.05 \pm 0.00$ & $0.03 \pm 0.00 \dagger$ & $0.06 \pm 0.01 \ddagger$ \\
\hline \multicolumn{4}{|l|}{$\mathrm{MDO}_{2}$} \\
\hline Baseline & $0.37 \pm 0.03$ & $0.39 \pm 0.05$ & $0.46 \pm 0.03$ \\
\hline Reperfusion & $0.30 \pm 0.04$ & $0.26 \pm 0.03$ & $0.53 \pm 0.05^{*} \neq$ \\
\hline \multicolumn{4}{|l|}{ Lactate } \\
\hline Baseline & $-2.87 \pm 0.40$ & $-1.75 \pm 0.52$ & $-2.49 \pm 0.35$ \\
\hline Reperfusion & $-5.63 \pm 0.98$ & $-2.32 \pm 0.51^{*}$ & $-2.99 \pm 0.42 \dagger$ \\
\hline
\end{tabular}

To the best of our knowledge, for the first time in the present study acute administration of a selective $\mathrm{ET}_{\mathrm{A}}$ receptor antagonist showed similar results in failing rat hearts. Using both selective $\mathrm{ET}_{\mathrm{A}}{ }^{18,19}$ and unselective $\mathrm{ET}_{\mathrm{A}} / \mathrm{ET}_{\mathrm{B}}{ }^{20,21}$ receptor blockers, we demonstrated a close relationship between the endothelin system and nitric oxide, suggesting that the protective effect of ERA was mediated by enhancing the bioavailability of nitric oxide und consequently preserving endothelial function.

Similar results can be achieved by the administration of angiotensin-converting enzyme inhibitors during $\mathrm{I} / \mathrm{R}$ in isolated cardiomyocytes ${ }^{22}$ and as adjunct to cardioplegia in both nonfailing ${ }^{14,23}$ and failing ${ }^{24}$ hearts in isolated organ perfusion systems. These studies suggest a nitric oxide-induced mechanism as well preventing endothelial dysfunction and thereby enhancing postischemic myocardial function, metabolism, and ultrastructural integrity. In our laboratory in a protocol ${ }^{24}$ similar to that used in the current study, the administration of quinaprilat with Buckberg blood cardioplegic solution in failing rat hearts improved postischemic recovery of hemodynamic values and myocardial 



FIGURE 4. High-energy phosphates in biopsy tissue of the LV in the treatment groups receiving ERA compared with the control group. Changes in phosphocreatine and adenine nucleotide levels (A) and energy charge (B) in ERA the chronic and acute groups versus the control group; * $P<.01$ versus control; $\# P<.05$ versus control. $P C r$, Phosphocreatine; $A M P$, adenosine monophosphate; $A D M$, adenosine diphosphate; $A T P$, adenosine triphosphate.

energy metabolism. In the present study, long-term administration of TBC-3214Na after MI led to an attenuation of cardiac remodeling as indicated by reduced cardiac hypertrophy, reduced LV dilatation, and enhanced cardiac function indicated by baseline morphology and hemodynamic performance.

Similar results have been obtained in several studies using both selective and unselective ERA in animal models of heart failure. ${ }^{25,26} \mathrm{The}_{\mathrm{ET}}$ blocker was started on day 3 after MI because when started earlier negative effects on infarct healing, scar formation, and LV remodeling have been reported. ${ }^{27,28}$ A reduction of $\mathrm{LV}$ diameter diminishes wall tension according to the law of LaPlace. This is accompanied by a reduction of LV mass and consecutively reduced oxygen consumption. Thereby the positive influence on LV geometry and metabolism enhances myocardial tolerance to I/ R. This might serve as an explanation for the improvement of postischemic recovery of cardiac function compared with control despite no enhancement in coronary artery blood flow when TBC-3214Na is administered chronically and standard cardioplegic solution is used during I/R. Another possible mechanism for the difference between acute and chronic treatment is the fact that during $I / R$ there is a massive increase in ET-1 levels arising from injured tissue. Only in the acute treatment group is the $\mathrm{ET}_{\mathrm{A}}$-blocker present at relevant concentrations in the perfusion medium at the time point and site of injury. Therefore, the superiority of acute versus chronic administration of ERA in preserving endothelial function renders the use of ERA as adjunct to cardioplegia only during I/R. Further research, however, is needed to get clear insight into the entire mechanism behind the differences observed between acute and chronic administration and the potentially positive effect of ERA when used in the setting of the cardiac operating room.

As a conclusion from this study and other experimental data with direct and indirect nitric oxide donors, the crucial point especially in failing hearts with impaired diastolic and systolic function lies in nitric oxide bioavailability during I/ R. By enhancement of nitric oxide bioavailability, two major problems of hypertrophied, remodeled hearts can be attenu- ated: diastolic dysfunction, indicated by reduced diastolic relaxation, leading to systolic dysfunction, and enhanced metabolic demand caused by myocardial hypertrophy. Therefore, ERA provides an interesting pharmacologic profile by (1) counteracting the detrimental effects of ET-1 in I/ $\mathrm{R}$ and heart failure and by (2) enhancing nitric oxide bioavailability. Consequently, acute ERA as an adjunct to current cardioplegic techniques may provide an additional benefit in patients with poor ejection fraction by preserving endothelial function and improving myocardial protection.

\section{References}

1. Krämer BK, Ittner KP, Beyer ME, Hoffmeister HM, Riegger GAJ. Circulatory and myocardial effects of endothelin. J Mol Med. 1997;75:886-90.

2. Benigni A, Remuzzi G. Endothelin antagonists. Lancet. 1999;353:133-8.

3. Pernow J, Wang Q- D. Endothelin in myocardial ischaemia and reperfusion. Cardiovasc Res. 1997;33:518-26.

4. Hosada K, Nakao K, Arai H, Suga S, Ogawa Y, Mukoyama M, et al. Cloning and expression of human endothelin-1 receptor cDNA. FEBS Lett. 1991;287:23-6.

5. Ogawa Y, Nakao K, Arai H, Nakagawa O, Hosoda K, Suga S, et al. Molecular cloning of a non-isopeptideselective human endothelin receptor. Biochem Biophys Res Commun. 1991;178:248-55.

6. Hiramatsu T, Forbess J, Miura T, Roth SJ, Cioffi MA, Mayer JE. Effects of endothelin-1 and endothelin-A recptor antagonist on recovery after hypothermic cardioplegic ischemia in neonatal lamb hearts. Circulation. 1995;92:400-4.

7. Goodwin AT, Amrani M, Gray CC, Chester AH, Yacoub MH. Inhibition of endogenous endothelin during cardioplegia improves low coronary reflow following prolonged hypothermic arrest. Eur J Cardiothorac Surg. 1997;11:981-7.

8. Li X-S, Wang Q-D, Pernow J. Beneficial effects of the endothelin receptor antagonist bosentan on myocardial and endothelial injury following ischemia reperfusion in the rat. Eur J Pharmacol. 1995;283:161-8.

9. Brunner F, Opie LH. Role of endothelin-A receptors in ischemic contracture and reperfusion injury. Circulation. 1998;97:391-8.

10. Ozdemir R, Parlakpinar H, Polat A, Colak C, Ermis N, Acet A. Selective endothelin a receptor antagonist (BQ-123) reduces both myocardial infarct size and oxidant injury. Toxicology. 2006;219:142-9.

11. Trescher K, Bernecker O, Fellner B, Semsroth S, Ullrich R, de Martin R, et al. Adenovirus-mediated overexpression of inhibitor kappa B-alpha attenuates postinfarct remodeling in the rat heart. Eur J Cardiothorac Surg. 2004;26:960-7.

12. Podesser BK, Hallstroem S, Schima H, Huber L, Weisser J, Kröner A, et al. The erythrocyte perfused "working heart"' model: hemodynamic and metabolic performance in comparison to crystalloid perfused hearts. J Pharmacol Toxicol Methods. 1999;41:9-15.

13. Trescher K, Bernecker O, Fellner B, Gyongyosi M, Schäfer R, Aharinejad S, et al. Inflammation and postinfarct remodeling: overexpression of IkappaB prevents ventricular dilation via increasing TIMP levels. Cardiovasc Res. 2006;69:746-54.

14. Korn P, Kröner A, Schirnhofer J, Hallström S, Bernecker O, Mallinger R, et al. Quinaprilat during cardioplegic arrest in the rabbit heart to prevent ischemiareprfusion injury. J Thorac Cardiovasc Surg. 2002;124:352-60. 
15. Dworschak M, Franz M, Hallström S, Semsroth S, Gasser H, Haisjackl M, et al. Snitroso human serum albumin improves oxygen metabolism during reperfusion after severe myocardial ischemia. Pharmacology. 2004;72:106-12.

16. Hallström S, Gasser H, Neumayer C, Fügl A, Nanobashvili J, Jakubowski A, et al. $\mathrm{S}$-Nitroso human serum albumin treatment reduces ischemia/reperfusion injury in skeletal muscle via nitric oxide release. Circulation. 2002;105:3032-8.

17. Schaper J, Mulch J, Winkler B, Schaper W. Ultrastructural, functional and biochemical criteria for estimation of reversibility of ischemic injury: a study on the effects of global ischemia on the isolated dog heart. J Mol Cell Cardiol. 1979;11:521-41.

18. Gonon AT, Gourine AV, Pernow J. Cardioprotection from ischemia and reperfusion injury by an endothelin A-receptor antagonist in relation to nitric oxide production. J Cardiovasc Pharmacol. 2000;36:405-12.

19. Gourine AV, Gonon AT, Pernow J. Involvement of nitric oxide in cardioprotective effect of endothelin receptor antagonist during ischemia reperfusion. Am J Physiol Heart Circ Physiol. 2001;280:H1105-12.

20. Gonon AT, Erbas D, Bröijersen A, Valen G, Pernow J. Nitric oxide mediates protective effect of endothelin receptor antagonism during myocardial ischemia and reperfusion. Am J Physiol Heart Circ Physiol. 2004;286:1767-74.

21. Wang QD, Li XS, Pernow J. The nonpeptide endothelin receptor antagonist bosentan enhances myocardial recovery and endothelial function during reperfusion of the ischemic rat heart. J Cardiovasc Pharmacol. 1995;26:S445-7.
22. Matoba S, Tasumi T, Keira N, Kawahara A, Akashi K, Kobara M, et al. Cardioprotective effect of ACE inhibition against hypoxia/reoxygenation injury in cultured rat cardiac myocytes. Circulation. 1999;99:817-22.

23. Kitakaze M, Minamino T, Node K, Komamura K, Shinozaki Y, Mori H, et al. Beneficial effects of inhibition of ACE on ischemic myocardium during coronary hypoperfusion in dogs. Circulation. 1995;92:950-61.

24. Podesser BK, Schirnhofer J, Bernecker OY, Kröner A, Franz M, Semsroth S, et al Optimizing ischemia/reperfusion in the failing rat heart-improved myocardial protection with acute ACE inhibition. Circulation. 2002;106:277-83.

25. Sakai S, Miyauchi T, Kobayashi M, Yamaguchi I, Goto K, Sugishita Y. Inhibition of myocardial endothelin pathway improves long-term survival in heart failure. Nature. 1996;384:353-5.

26. Podesser BK, Siwik DA, Eberli FR, Sam F, Ngoy S, Lambert J, et al. ETA-receptor blockade prevents matrix metalloproteinase activation late postmyocardial infarction in the rat. Am J Physiol Heart Circ Physiol. 2001;280:984-91.

27. Hu K, Gaudron P, Schmidt TJ, Hoffmann KD, Ertl G. Aggravation of left ventricular remodeling by a novel specific endothelin ET (A) antagonist EMD 94246 in rats with experimental myocardial infarction. J Cardiovasc Pharmacol. 1998;32: 505-8.

28. Nguyen QT, Cernacek P, Calderoni A, Stewart DJ, Picard P, Sirois P, et al. Endothelin A receptor blockade causes adverse LV remodeling but improves pulmonary artery pressure after infarction in the rat. Circulation. 1998;98:2323-30. 

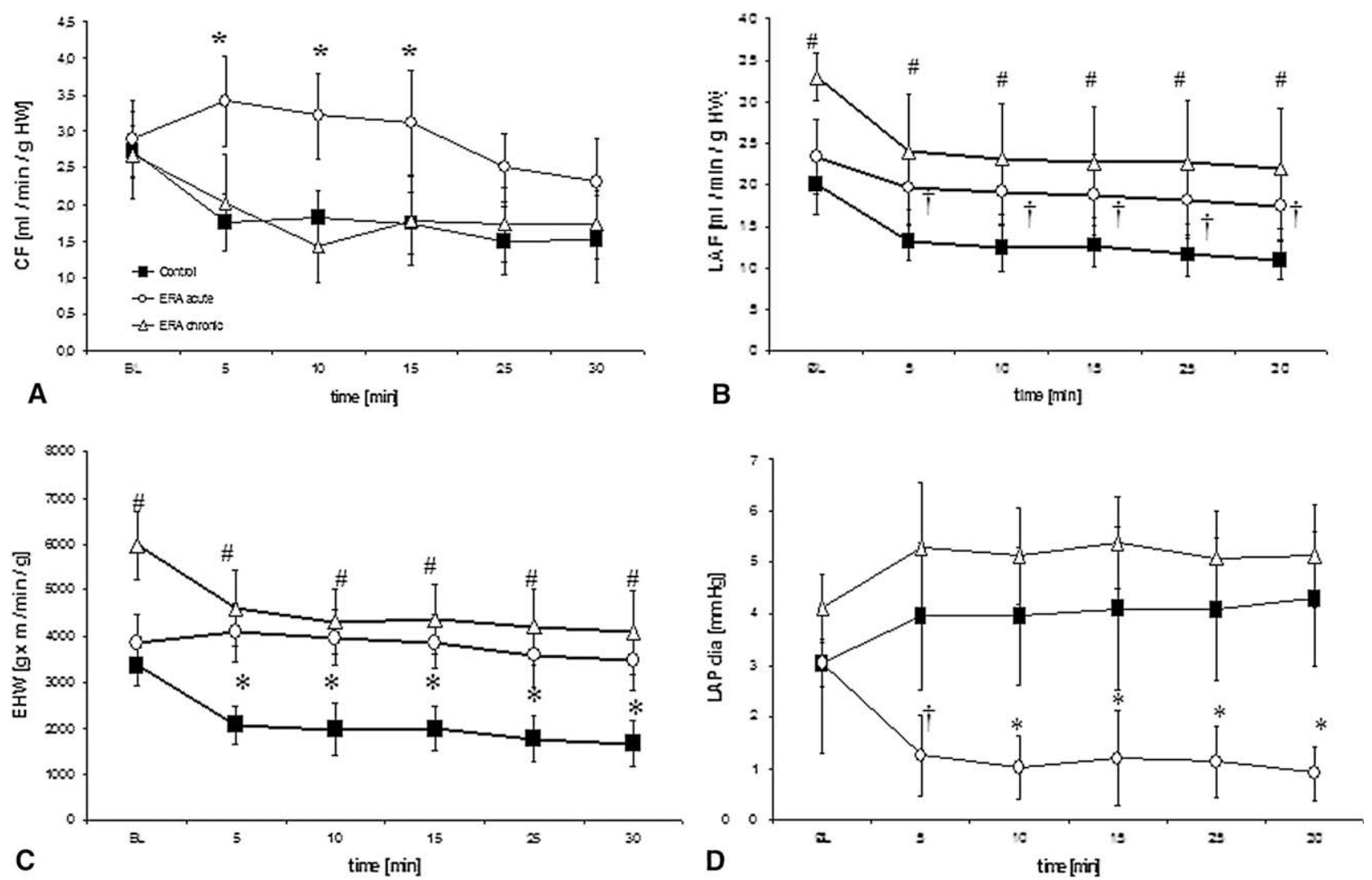

FIGURE E1. Ex vivo hemodynamic measurements in absolute values. A: Coronary flow $(C F)$. ERA acute versus both ERA chronic and control groups; ${ }^{*} P<$ .01. B, Cardiac output (left atrial flow, $L A F$ ). ERA acute versus control group, $\nmid P<.05$; ERA chronic versus control group, \#P<.01. C, External heart work $(E H W)$ (cardiac output $\times$ LV systolic pressure). ERA acute versus control group, $* P<.01$; ERA chronic versus control group; $\# P<.01$. D, Diastolic left atrial pressure $(L A P$ dia $) . * P<.01$ ERA acute versus control group. All data are presented as mean \pm SEM. $B L$, Baseline.

TABLE E1. With sham-operated group

Control $(n=12)$

ERA chronic $(\mathbf{n}=\mathbf{1 5})$

ERA acute $(\mathbf{n}=\mathbf{1 2})$

Sham-operated $(n=8)$

Part I: Echocardiographic data

$\operatorname{LVEDD}(\mathrm{cm})$

$1.14 \pm 0.05$

$1.01 \pm 0.06$

$0.28 \pm 0.04$

$\mathrm{EF}$

Part II: Baseline working heart data

$\mathrm{CF}\left(\mathrm{mL} \cdot \mathrm{min}^{-1} \cdot \mathrm{g}^{-1} \mathrm{HW}\right)$

$\mathrm{CO}\left(\mathrm{mL} \cdot \mathrm{min}^{-1} \cdot \mathrm{g}^{-1} \mathrm{HW}\right)$

$2.72 \pm 0.35$

$20.06 \pm 3.68$

EHW $\left(\mathrm{g} \times \mathrm{m} \cdot \min ^{-1} \cdot \mathrm{g}^{-1}\right)$

$1.01 \pm 0.01^{*}$
$0.82 \pm 0.01^{*}$
$0.82 \pm 0.01^{*}$
$2.71 \pm 0.48$
$32.94 \pm 2.86^{*}$
$5963 \pm 737^{*}$

$5963 \pm 737^{*}$

$$
\begin{aligned}
1.2 & \pm 0.04 \\
1.05 & \pm 0.02 \\
1.05 & \pm 0.02 \\
2.89 & \pm 0.51 \\
22.98 & \pm 4.62 \\
3862 & \pm 613
\end{aligned}
$$

$0.92 \pm 0.04 \dagger$

$0.63 \pm 0.04 \dagger$

$0.63 \pm 0.04 \dagger$

$4.2 \pm 0.59 \dagger$

$58.46 \pm 14.26 \dagger$

$7098 \pm 483 \dagger$

$* P<.05$ vs both control and ERA acute. $\dagger P<.05$ vs control, ERA acute, and ERA chronic. 